\title{
A sazonalidade de contaminantes em águas subterrâneas e superficiais entorno de um aterro sanitário na região Amazônica
}

A qualidade dos recursos hídricos amazônicos é muito importante para a manutenção da vida e da biodiversidade do bioma. 0 avanço da urbanização da região Norte do Brasil, aumenta a degradação desses recursos, principalmente, pela falta de saneamento básico na maioria das cidades. Santarém é um município localizado no Oeste do Pará, e nos últimos anos passa por um período de expansão urbana, que provoca a degradação dos recursos hídricos subterrâneos e superficiais, devido ao descarte de efluentes in natura em igarapés e a falta de informação na construção de fossas sépticas. O presente estudo avaliou a sazonalidade dos contaminantes, como nitrito/nitrato, fósforo, fosfato e coliformes termotolerantes (E. Coli) e parâmetros físico-químicos, nas estações seca e chuvosa, entre 2018 e 2019, em 9 amostras de água, sendo, 6 de água subterrânea e 3 de água superficial de comunidades entorno do aterro sanitário da cidade de Santarém, PA. Os resultados mostraram uma diferença entre a estação seca e chuvosa, sendo a última com as maiores concentrações para os contaminantes. Em uma amostra houve o aumento de 1520 vezes mais na estação chuvosa em comparação à estação seca em relação a E. Coli. Ainda assim, para a maioria dos parâmetros há conformidade com as normas brasileiras CONAMA 357/05 e CONAMA 396/08. As diferenças nas concentrações dos contaminantes em ambas as estações pode estar relacionada à falta de saneamento básico na região, que a impõe a construção de fossas sépticas e negras aos moradores.

Palavras-chave: Amazônia; Parâmetros físico-químicos; CONAMA; Saneamento básico.

\section{The seasonality of contaminants in groundwater and surface water surrounding a landfill in the Amazon region}

\begin{abstract}
The quality of Amazonian water resources is very important for the maintenance of life and biodiversity in the biome. The advance of urbanization in northern Brazil increases the degradation of these resources, mainly due to the lack of basic sanitation in most cities. Santarém is a municipality located in the west of Pará, and in recent years is going through a period of urban expansion, which causes the degradation of underground and surface water resources, due to the disposal of effluents in natura in streams and the lack of information in the construction of septic tanks. This study assessed the seasonality of contaminants, such as nitrite/nitrate, phosphorus, phosphate and thermotolerant coliforms (E. Coli) and physical-chemical parameters, in the dry and rainy seasons, between 2018 and 2019, in 9 water samples, 6 of which were groundwater and 3 were surface water from communities surrounding the landfill in the city of Santarém. The results showed a difference between the dry and rainy seasons, the latter with the highest concentrations for contaminants. In one sample, there was a 1520 -fold increase in the rainy season compared to the dry season for E. Coli. Even so, for most parameters there is compliance with the Brazilian legislation CONAMA 357/05 and CONAMA 396/08. The differences in concentrations of contaminants in both seasons may be related to the lack of basic sanitation in the region, which imposes the construction of septic and black pits on residents.
\end{abstract}

Keywords: Amazonia; Physicochemical parameters; CONAMA; Basic sanitation.

Topic: Engenharia Ambiental

Reviewed anonymously in the process of blind peer.
Received: 04/10/2020

Approved: 24/11/2020
Igor Costa

Universidade Federal do Oeste do Pará, Brasil

http://lattes.cnpq.br/5371681633660542

igorcosta@gmail.com

Edinelson Correa Saldanha (iD)

Universidade da Amazônia, Brasil

http://lattes.cnpq.br/0344768485868201

http://orcid.org/0000-0002-4162-4296

edinelson_saldanha@hotmail.com

Christiane do Nascimento Monte

Universidade Federal do Oeste do Pará, Brasil

http://lattes.cnpq.br/6178162183692365

http://orcid.org/0000-0003-4840-7777

christiane.monte@yahoo.com.br
Referencing this:

COSTA, I.; SALDANHA, E. C.; MONTE, C. N.. A sazonalidade de contaminantes em águas subterrâneas e superficiais entorno de um aterro sanitário na região Amazônica. Revista Ibero Americana de Ciências Ambientais, v.11, n.6, p.371-382, 2020. DOI:

http://doi.org/10.6008/CBPC2179-6858.2020.006.0030 


\section{INTRODUÇÃO}

A água é um elemento essencial, e serve como mecanismo de manutenção à vida no planeta. Seus múltiplos usos são indispensáveis a um largo espectro das atividades humanas, o que se destaca, entre outros, o abastecimento doméstico e público; os usos agrícola e industrial; produção de energia elétrica e as atividades de lazer e recreação (FRANÇA et al., 2019), e, também nos processos hídricos ou físico-químicos que ocorrem na fauna e flora em todo o planeta.

O uso ou consumo da água pelos seres humanos acaba se tornando algo mais refinado, por possui uma relação direta com a qualidade e quantidade, sendo os mesmos parâmetros cada vez mais exigidos. Este fato pode ser dado a grande expansão urbana, industrial e agrícola aliado ao crescimento populacional descontrolado, fazendo com que a demanda por este recurso aumente (SANTOS et al., 2018; SILVA et al., 2019).

A disponibilidade de água possui relação direta com formas de uso da terra, como a compactação, impermeabilização, desmatamento, aterramentos (TUCCI, 2016), fazendo com que as ações antrópicas contribuam significativamente para mudanças na qualidade da água e levando a degradação deste recurso (BRITTO et al., 2018). Logo, a população é considerada como agente ou até mesmo um fator que influencia em alterar a qualidade dos corpos hídricos existentes em todas as suas formas.

Nem todo recurso hídrico possui características necessárias a serem consumidas pelo ser humano. Para avaliação da qualidade dos recursos hídricos, atualmente têm-se a adoção de metodologias de parâmetros físico-químicos e microbiológicos ao qual se somam outros parâmetros específicos, servem para avaliar a qualidade da água (corpos hídricos), mas seus indicadores variam de acordo com o uso e ocupação do solo na região de influência direta do ponto de amostragem (FRANÇA et al., 2019).

O conhecimento destas interações é de extrema importância para que se possa lidar da melhor forma possível com as fontes de poluição (PEREIRA et al., 2013), ou na forma mais acentuada, contaminação. A contaminação dos recursos hídricos pode estar relacionada aos efluentes domésticos e industriais, fertilizantes, agrotóxicos e lixões (SILVA JUNIOR et al., 2019; PINHEIRO et al., 2019).

O lixão pode ser conceituado como um depósito de resíduos ou rejeitos in natura, originados da construção civil, hospitalar, doméstico, industrial, dentre outros (SILVA JUNIOR et al., 2019). Os lixões podem causar a poluição do solo, das águas superficiais e subterrâneas pelo escoamento superficial ou percolação de lixiviados. Contudo, não excluindo agentes de influência a contaminação, no caso, a população.

Os aterros sanitários, são áreas de tratamento baseado em técnicas sanitárias de impermeabilização do solo, compactação e cobertura diária das células de lixo, coleta e tratamento de gases, bem como tratamento do chorume, entre outros procedimentos técnico-operacionais responsáveis por evitar os aspectos negativos da deposição final do lixo (PORTELLA et al., 2014). Permitindo uma confinação segura em termos de controle da poluição ambiental e proteção ao meio ambiente, mesmo assim existem riscos ao ambiente, uma vez que, se a mesma não for bem executada, pode possibilitar a percolação do lixiviado, contaminando o solo e as águas subterrâneas (SIZIRICl et al., 2015). De tal maneira, a minimizar os danos às 
águas superficiais, o lixiviado gerado no aterro deve ser coletado e tratado adequadamente (DIA et al., 2018).

O chorume é somente o líquido proveniente da decomposição da matéria orgânica, e os lixiviados e/ou percolados são a solução do chorume e água, de origem superficial (chuva ou escoamento) (SÁ et al., 2012), com carga potencialmente poluidora que pode gerar grande impacto ao meio ambiente (SANTOS, 2008). Por ter uma complexa combinação de poluentes com características toxicológicas persistentes, o lixiviado, possuindo diferentes contaminantes orgânicos e inorgânicos recalcitrantes, tais como ácidos húmicos e fúlvicos, hidrocarbonetos policíclicos aromáticos, pesticidas, elementos-traço e altos níveis de nitrogênio amoniacal, que pode contaminar os aquíferos ao seu entorno, assim como as águas superficiais (REGADíO et al., 2012; Ll et al., 2014; VIEIRA et al., 2020).

Outro fator que provoca a contaminação é a falta de saneamento básico em diversas regiões brasileira, sendo a mais atingida, a região Norte do país (LAUTHARTTE et al., 2016). A construção de fossas sépticas e negras, muitas vezes mal construídas, contaminam as águas subterrâneas e superficiais (LAUTHARTTE et al., 2016; MESCHEDE et al., 2018)

O Aterro de Perema, situado na comunidade de Perema, no km 14 da rodovia Santarém/Curuá-Una, é o principal destino para todo o lixo (resíduos urbanos) produzido no município de Santarém, sendo o mesmo composto por materiais orgânicos e inorgânicos, e, também são depositados os resíduos gerados pelos hospitais maiores (coleta especial da Prefeitura) e o restante de o lixo hospitalar (clínicas, ambulatórios, farmácias etc.) é despejado juntamente com os outros tipos de materiais (CRUZ et al., 2017). Conquanto, a deposição de produto no local sem o tratamento adequado vem causando inúmeros impactos socioambientais na região, e, devido a este funcionamento precário, é classificado pelo Mistério Público como lixão (OLIVEIRA, 2014).

Nesse sentido, o gerenciamento dos recursos hídricos é ferramenta importante para o crescimento e desenvolvimento da sociedade. Os estudos que tratam da interação entre os sistemas hídricos atmosférico, superficial e subterrâneo têm sido de grande importância para seu gerenciamento (SILVA et al., 2010), fezse o uso da Geoquímica da água que é considerado um instrumento de apoio, usado em diversas áreas para a avaliação da qualidade dos corpos hídricos.

Segundo a contribuição de Oliveira et al. (2018) embora que os conhecimentos físico-químicos e bioquímicos nas águas facilitem a interpretação de dados hidroquímicos, o uso da água como geoindicador de qualidade ambiental, é uma das formas de gestão ambiental, logo, salvaguardar o acompanhamento da qualidade da água para consumo humano deve ser uma atividade rotineira, preventiva, e de ação do sistema público. Para que seja possível garantir o conhecimento da sua situação, resultando na redução das possibilidades de enfermidades transmitidas pela água (BRASIL, 2005; FAÇANHA, 2016).

O objetivo deste trabalho foi a caracterização hidrogeoquímica, observando a influência da sazonalidade parâmetros analisados, através de análises em águas superficiais e subterrâneas em áreas adjacentes ao aterro do Perema, na comunidade do Perema e nas comunidades ao seu entorno, na Cidade de Santarém (PA), bem como comparar os valores encontrados com os valores máximos permissíveis - VMP nas normas Resolução no 357/2005, referente às águas superficiais e na Resolução no 396/2008 para águas 
subterrâneas, do CONAMA - Conselho Nacional de Meio Ambiente.

\section{METODOLOGIA}

A área abrangida pelo estudo compreende a comunidade do Perema, localizada no município de Santarém, situada à margem direita da confluência dos Rios Tapajós e Amazonas, município brasileiro do estado do Pará, pertencente à Mesorregião do baixo Amazonas. Seus domínios estão dentro da bacia hidrográfica do rio Amazonas (TANCREDI, 1996), localizado no extremo norte brasileiro, a uma Latitude: 02으 26' 35" S e a uma Longitude: 54은 $42^{\prime} 30$ " W.

O Aterro de Perema (Figura 1) localiza-se distante aproximadamente $14 \mathrm{~km}$ do centro da Cidade, no km 15 da rodovia PA- 370, a Santarém - Curuá-Una. Possui uma área de 68 hectares, e no seu entorno estão as comunidades de Castela, Miritituba, Mararu, Perema, Estrada Nova e Cristo Rei (SEMMA, 2013).

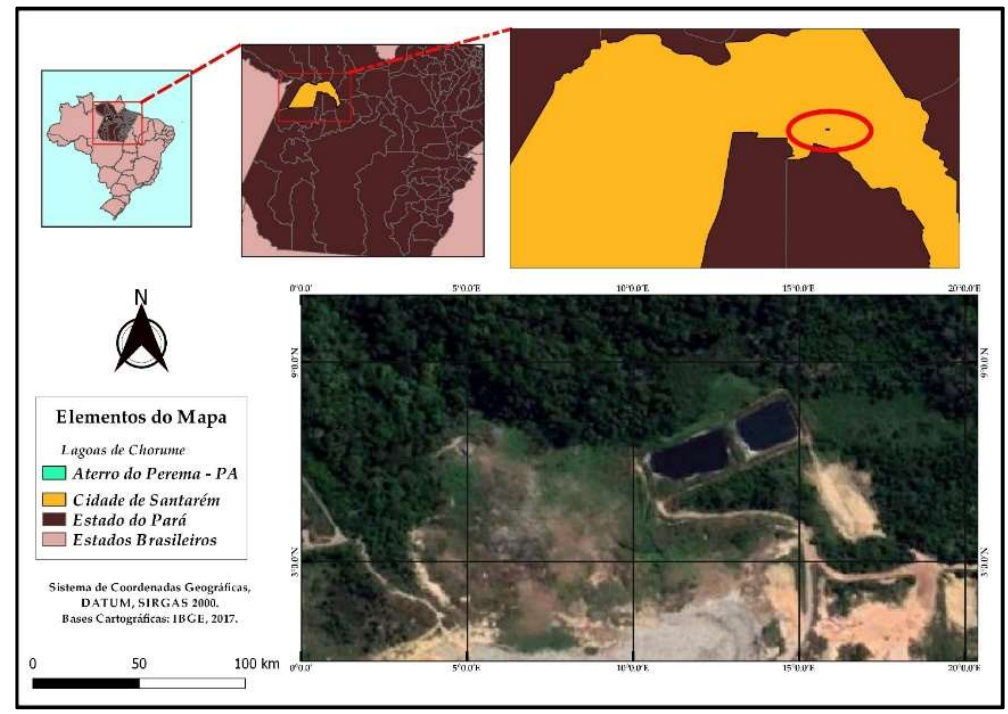

Figura 1: Localização Geral e da área de pesquisa.

A região apresenta clima tipo Am, segundo classificação de Köppen, caracterizado por apresentar índice pluviométrico anual elevado e moderado período de estiagem, com elevadas temperaturas, sem mudanças significativas (TSUKAMOTO FILHO et al., 2007). Sua estação chuvosa está entre janeiro a junho com totais médios acumulados da ordem de $400 \mathrm{~mm}$, e estação seca, abrange os meses de agosto a novembro, com variações em torno de 0 a $100 \mathrm{~mm}$, sendo julho e dezembro considerados meses de transição (SOUZA et al., 2004).

Foram realizadas duas campanhas (coletas) de água superficial (Asup) e água subterrâneas (Asub) no mês de julho/2018 (seca) e fevereiro/2019(chuva), em uma área amostral de nove pontos ao entorno do aterro (Figura 2). Nas duas campanhas foram obtidas dezoito amostras: sendo seis amostras de água subterrânea, coletadas em poços cacimbas e tubulares de residências no entorno do aterro e três de água superficial no Igarapé do Miritituba.

Os parâmetros analisados nas amostras de água, foram: $\mathrm{pH}$, Oxigênio Dissolvido (O.D) (mg/L), condutividade elétrica (C.E) $(\mu \mathrm{S})$, temperatura e nutrientes $(\mathrm{mg} / \mathrm{L})$, como fosforo/fosfato, nitrito e nitrato, além de bacteriológicos, como Coliformes Totais e Termotolerantes (NMP/1000). 


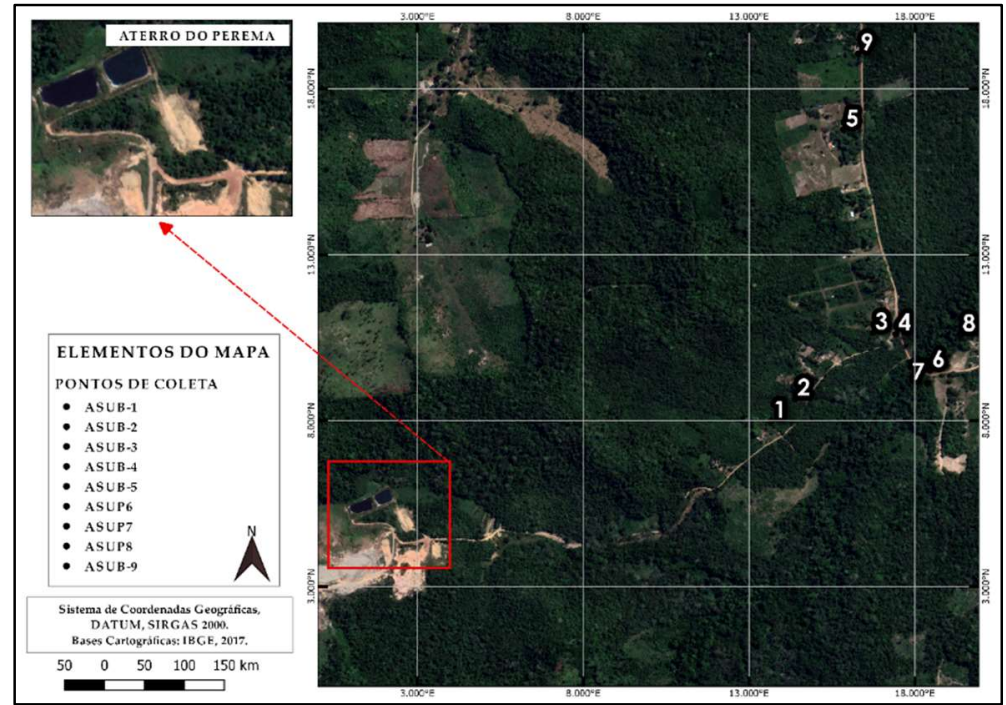

Figura 2: Área amostral dos pontos em relação ao Aterro do Perema, Santarém/PA.

As metodologias de análises para a determinação dos nutrientes (parâmetros químicos): nitrito, nitrato, fósforo e fosfato, foram baseadas no método colorimétrico e leitura em espectrofotômetro de absorção atômica, desenvolvido por Grasshoff (1983). Para as análises de coliformes, foi realizado o método de membrana filtrante, e para os procedimentos de análises de pH, O.D, C.E e Temperatura, foram realizados nos equipamentos multiparâmetro AKSO modelo AK88, sonda Lovi Bond/Senso Direct 150 e no turbimetro Poli Control/AP 2000. Foi aplicado teste estatístico de Wilcoxon $(p<0,05)$ utilizando o software estatístico Statistica versão 7.

\section{RESULTADOS}

Os parâmetros físico-químicos não mostraram grandes variações na estação seca (Tabela 1). O pH apresentou característica ácida, típico da formação Alter do Chão, a condutividade elétrica (C.E) foi maior nos pontos 3 e 5, o que indica maior presença de sais na água, que pode ser um indício de contaminação por esgoto. O oxigênio dissolvido (O.D) foi maior entre as amostras de água subterrânea no ponto 6, e está relacionado ao tipo de poço, que neste caso era cacimba, o que há maior contato com a superfície.

Tabela 1: Parâmetros Físico-químicos na estação seca.

\begin{tabular}{l|lll}
\multicolumn{1}{l}{ Ponto } & $p H$ & Condutividade Elétrica $(\mu \mathrm{S})$ & Oxigênio Dissolvido $(\mathrm{mg} / \mathrm{L})$ \\
\hline ASUB-1 & 5,9 & 39,2 & 3,8 \\
ASUB-2 & 5,9 & 176,3 & 4,2 \\
ASUB-3 & 4,7 & 24,8 & 5,5 \\
ASUB-4 & 5,8 & 49 & 4,4 \\
ASUB-5 & 5,9 & 72,4 & 5 \\
ASUB-6 & 5,8 & 9,3 & 6,3 \\
ASUP7 & 5,8 & 14,2 & 5,4 \\
ASUP8 & 5,6 & 11,9 & 5 \\
ASUP9 & 5,6 & 11,4 & 5,3
\end{tabular}

Na estação chuvosa, os parâmetros físico-químicos mostraram tendências diferentes da estação seca (Tabela 3). $\mathrm{O} \mathrm{pH}$ foi mais baixo em todos os pontos, sendo mais ácido na estação chuvosa do que na estação seca, o que sugere maior influência da formação Alter do Chão. Na maioria dos pontos de água subterrânea a condutividade elétrica foi maior, o que pode estar relacionada a maior concentração de sais vindos com a 
percolação da água da chuva no solo. O oxigênio dissolvido foi menor em todos os pontos, o que pode ser relacionada a maior recarga do aquífero, o que diminui a entrada de oxigênio.

Tabela 3: Parâmetros Físico-químicos na estação chuvosa.

\begin{tabular}{l|lll}
\multicolumn{1}{l|}{ Ponto } & $p H$ & Condutividade Elétrica $\mu \mathrm{S})$ & Oxigênio Dissolvido $(\mathrm{mg} / \mathrm{L})$ \\
\hline ASUB-1 & 4,3 & 57,6 & 3 \\
ASUB-2 & 3,8 & 320 & 1,2 \\
ASUB-3 & 4,5 & 45 & 2,6 \\
ASUB-4 & 4,8 & 22 & 1,8 \\
ASUB-5 & 4 & 30 & 2,2 \\
ASUB-6 & 5,5 & 16,3 & 2,8 \\
ASUP7 & 4,8 & 11,3 & 1,4 \\
ASUP8 & 4,9 & 15,9 & 4,7 \\
ASUP9 & 4,8 & 29,2 & 2,8
\end{tabular}

Ao aplicar de Wilcoxon nas amostras de OD nas estações seca e chuvosa, foi visto diferença estatística entre as amostras $(Z=2,66 ; p<0,05)$, assim como foi visto diferença estatística entre as amostras de $\mathrm{pH}$ em ambas as estações $(Z=2,67 ; p<0,05)$.

Todos os pontos apresentaram em conformidade com a CONAMA 396/08 e com a CONAMA 357/05 para nutrientes (Tabela 2). Entretanto os pontos 4 e 5 apresentaram concentrações de nitrato até 220 vezes maior (ponto 5) que a maioria dos pontos, sugerindo que há contaminação por esgoto ou por outras fontes de contaminação.

Tabela 2: Concentrações de Fosfato, Fósforo, Nitrito e Nitrato (mg/L) - na estação seca.

\begin{tabular}{l|llll}
\multicolumn{1}{l}{ Ponto } & Fosfato $(\mathrm{mg} / \mathrm{L})$ & Fósforo $(\mathrm{mg} / \mathrm{L})$ & Nitrato $(\mathrm{mg} / \mathrm{L})$ & Nitrito $(\mathrm{mg} / \mathrm{L})$ \\
\hline ASUB-1 & 0,01 & 0,01 & 0,01 & 0,09 \\
ASUB-2 & 0,01 & 0,01 & 0,41 & 0,09 \\
ASUB-3 & 0,02 & 0,01 & 0,01 & 0,08 \\
ASUB-4 & 0,01 & 0,01 & 1,33 & 0,08 \\
ASUB-5 & 0,01 & 0,01 & 2,20 & 0,00 \\
ASUB-6 & 0,01 & 0,01 & 0,01 & 0,12 \\
ASUP7 & 0,01 & 0,01 & 0,01 & 0,09 \\
ASUP8 & 0,01 & 0,01 & 0,01 & 0,09 \\
ASUP9 & 0,01 & 0,01 & 0,01 & 0,00
\end{tabular}

No período chuvoso, as concentrações de todos os nutrientes, em todos os pontos, aumentaram ao comparar com o período seco (Tabela 3), mostrando a influência da sazonalidade nos resultados. As concentrações de nitrato variaram de 6 vezes mais (ponto 7) a 255 vezes a mais (ponto 1) em comparação à estação seca. As concentrações de nitrito, fósforo e fosfato também aumentaram em relação à estação seca na maioria dos pontos. Essa variação indica uma influência de contaminação por esgoto ou por outra fonte, que libere matéria orgânica em decomposição. Ao comparar com a CONAMA 396/08, o ponto 5 não está conformidade com a norma, indicando contaminação.

Os resultados de fósforo no período chuvoso, mostram que as amostras de águas superficiais estão em conformidade com Resolução CONAMA no 357/2005, que estabelece o valor máximo permitido em cursos d'água de $0,1 \mathrm{mg} / \mathrm{L}$. As amostras de águas subterrâneas estão em conformidade com a resolução do CONAMA, 396/08, que o limite é 0,025 mg/L. Foi aplicado o teste estatístico de Wilcoxon e houve diferença entre as amostras de fosfato em ambas as estações estudadas, sendo o aumento significativo na estação chuvosa $(Z=2,52 ; p<0,05)$; entre as amostras de fósforo houve diferença estatisticamente significativa entre 
a estação seca e chuvosa $(Z=2,02 ; p<0,05)$.

Tabela 3: Concentrações de Fosfato, Fósforo, Nitrito e Nitrato (mg/L) - estação chuvosa.

\begin{tabular}{l|llll} 
Ponto & Fosfato(mg/l) & Fósforo(mg/l) & Nitrato $(\mathrm{mg} / \mathrm{l})$ & Nitrito(mg/l) \\
\hline ASUB-1 & 0,09 & 0,03 & 2,55 & 0,08 \\
ASUB-2 & 0,05 & 0,02 & 3,82 & 0,08 \\
ASUB-3 & 0,04 & 0,01 & 0,3 & 0,09 \\
ASUB-4 & 0,01 & 0 & 0,32 & 0,08 \\
ASUB-5 & 0,1 & 0,03 & 12,24 & 0,09 \\
ASUB-6 & 0,06 & 0,02 & 0,26 & 0,09 \\
ASUP7 & 0,07 & 0,02 & 0,06 & 0,09 \\
ASUP8 & 0,06 & 0,02 & 0,2 & 0,09 \\
ASUP9 & 0,05 & 0,02 & 0,1 & 0,09
\end{tabular}

Os resultados dos coliformes termotolerantes (E. Coli) (Tabela 4) mostram grande influência da sazonalidade, havendo um aumento de 1520 vezes na estação chuvosa em comparação com a estação seca no ponto 2. Ao comparar com as normas vigentes CONAMA 396/08 e CONAMA 357/05, oito pontos não estão conformidade, sendo um risco para saúde humana ao consumir as águas ou usar para irrigação de hortas. Além disso, esses resultados podem evidenciar a falta de saneamento básico na região, o que leva aos moradores a construírem fossas, algumas fossas negras, o agravamento da situação é relacionado ao desrespeito à distância mínima entre do poço e a fossa, contribuindo para a contaminação do aquífero.

Por outro lado, o aumento de coliformes termotolerantes pode estar relacionado ao escoamento do chorume das lagoas de estabilização na época chuvosa, o que pode contaminar o aquífero e as águas superficiais.

Tabela 4: Coliformes Termotolerantes (NMP/100). Coliformes Termotolerantes (NMP/1000) ESTAÇÃO SECA

Coliformes Termotolerantes (NMP/1000 ESTAÇÃO CHUVOSA

\begin{tabular}{l|ll} 
ASUB-1 & 0 & 0 \\
ASUB-2 & 0 & 1520 \\
ASUB-3 & 0 & 240 \\
ASUB-4 & 0 & 320 \\
ASUB-5 & 1200 & 640 \\
ASUB-6 & 0 & 400 \\
ASUP7 & 0 & 1120 \\
ASUP8 & 0 & 560 \\
ASUP9 & 0 & 320
\end{tabular}

\section{DISCUSSÃO}

\section{Parâmetros físico-químicos}

$\mathrm{O}$ pH ácido das águas é típico da região, devido solubilização das rochas da formação Alter do Chão, que é composta por rochas siliclásticas (MESCHEDE et al., 2018), o recomendado pela norma brasileira é entre 6,0 e 9,5. Apesar de baixo, outros estudos na região amazônica encontraram valores semelhantes aos encontrados neste estudo (LAUTHARTTE et al., 2016; GROTT et al., 2018; MESCHEDE et al., 2018; PINHEIRO et al., 2019). A ingestão de água ácida pode provocar irritação na pele e nas mucosas, assim como distúrbios gastrointestinais (WHO, 2003). A redução do pH na estação chuvosa pode estar relacionada ao aumento do intemperismo das rochas siliclásticas.

O oxigênio dissolvido mais baixo nas águas subterrâneas e superficiais menor na estação chuvosa 
pode estar relacionado à recarga do aquífero, que diminui os espaços vazios no aquífero, em relação às águas superficiais, pode estar relacionado à decomposição de matéria orgânica, que pode ser proveniente de esgoto, devido ao transbordamento das fossas e lavagem das margens.

\section{Fósforo e Fosfato}

O fósforo total dissolvido nos sistemas aquáticos pode ocorrer juntamente com a matéria orgânica, nele pode estar contido, como coloides orgânicos, ortofosfatos e polifosfatos (PAULA FILHO et al., 2012). O fosfato corresponde ao fósforo inorgânico dissolvido, que é a forma mais disponível aos organismos aquáticos e influencia diretamente na produção primária dos ecossistemas aquáticos (PAULA FILHO et al., 2012).

Freddo Filho (2018), em estudo na cidade de Benevides (PA), sobre aguas subterrâneas no período de agosto - dezembro, caracterizado como seco/menos chuvoso, observou que baixas concentrações de fosfato ocorrerem naturalmente em águas subterrâneas, pois está relacionado a processos naturais como a dissolução de rochas, decomposição de matéria orgânica e carreamento dos solos. Não ultrapassando a concentração de 0,05 mg.L-1, por conta da fácil fixação e baixa solubilidade de compostos fosfatados no solo.

Segundo Freddo Filho (2018) constatar concentrações de fosfato durante o período chuvoso (dezembro e março), de $0,085 \mathrm{mg} / \mathrm{L}$ a $3,215 \mathrm{mg} / \mathrm{L}$, foram elevadas as quais podem estar relacionadas à ausência de saneamento básico local. Aliado a isto, a ausência de um sistema complementar para tratamento dos efluentes domésticos em toda a área de estudo, como caixas de gorduras, o que pode influenciar no comportamento sazonal dos contaminantes (FREDDO FILHO, 2018).

Os Fosfatos são importantes para todas as formas de vida, porém em excesso nas águas tornam-se responsáveis pela eutrofização, isto é, provocam o crescimento acumulado de algas e bactérias heterótrofas, modificadoras do caráter físico-químico da água, diminuindo a quantidade de oxigênio dissolvido (LAFUENTE, 1989; FOPPA et al., 2004).

Pinheiro et al. (2019) encontraram maiores concentrações de fósforo no Igarapé do Irurá em Santarém em relação às amostras de água superficial deste estudo, sendo as maiores concentrações encontradas na estação chuvosa. Os autores relacionaram os resultados aos efluentes domésticos recebidos pelo corpo hídrico ao longo do seu percurso.

\section{Nitrato em águas subterrâneas}

Um dos principais contaminantes das águas subterrâneas é o nitrato, sendo suas fontes em áreas de ocupação antrópica associadas ao sistema sanitário (CONCEIÇÃO et al., 2014), o que inclui as construções precárias dos poços (SILVA et al., 2019). Fertilizantes, fossas sépticas ou negras, vazamentos nas redes esgotos são as principais fontes antrópicas de formas nitrogenadas (SILVA et al., 2019).

Castro (et al., 2014), ressaltam que o nitrato tem sido utilizado mundialmente como indicador da contaminação das águas subterrâneas, pois apresenta grande mobilidade na água subterrânea e persistência, devido não serem absorvidos pelo solo, podendo contaminar extensas áreas (PINHEIRO et al., 
2019). O que justifica a variação nas concentrações, os autores ainda afirmam, dentre os nutrientes, o nitrato é o mais móvel e estável, dadas as condições normalmente oxidantes dos aquíferos superficiais.

O estudo realizado na cidade de Benevides (PA), por Freddo Filho (2018), em águas subterrâneas, demonstrou concentrações anômalas do contaminante nitrato quando comparando dois períodos, ao qual foi observado maiores concentrações no chuvoso e menores no período menos chuvoso/seco. $\mathrm{O}$ autor ainda destaca que suas concentrações elevadas se dão pela proximidade às fossas negras e esgoto doméstico.

Azevedo (2006), através do estudo sobre abastecimento público sob águas subterrâneas da região de várzea de Urucará - AM, na Amazônia Central, destaca que ela apresenta em seu estado natural, boas condições de potabilidade. No entanto, o processo construtivo deficiente do poço tubular, pode comprometer esses aquíferos tornando-os mais vulneráveis a contaminação devido às próprias obras de captação.

Silva et al. (2007) após análise em poços em período de cheia local (chuvoso) e comparando com dados obtidos por Silva (2000), no período seco em Manaus. Os autores perceberam poços tubulares e escavados de baixo rendimento, explorando o lençol freático mais superficial, oferecendo abastecimento não tratado, sem monitoramento e proteção sanitária, em casos gerando potencial foco de contaminação.

Meschede et al. (2018) ao analisarem nitratos e outros íons em poços de escolas em Santarém e em Mojuí dos Campos, mostraram no estudo que as concentrações de nitrato estavam acima do permitido, e eram maiores no período chuvoso, a contaminação foi atribuída à proximidade das fossas aos poços, sendo um risco à saúde humana.

As grandes concentrações de nitrato na água podem causar diurese, danos ao baço e metaemoglobinemia (cianose), que é caracterizada pela substituição do oxigênio pelo $\mathrm{NO}_{2}^{-}$na hemoglobina do sangue, podendo levar à morte (COSTA et al., 2012; LAUTHARTTE et al., 2016).

\section{Parâmetros Microbiológicos}

De acordo Ceballos (2000) e Silva et al. (2018), E. coli é uma bactéria do grupo dos coliformes, encontrada nas fezes provinda do trato digestivo dos animais homeotérmicos, que pode causar doenças, como diarreia, hepatites e outros distúrbios gastrointestinais (MESCHEDE et al., 2018). Os resultados encontrados neste estudo mostraram que há a diferença no número de indivíduos entre as estações seca e chuvosa, sendo $90 \%$ das amostras na estação chuvosa apresentaram indivíduos acima do permitido pela norma brasileira (CONAMA 396/08 e portaria do Ministério da Saúde 2914 / 11. Os valores estão de acordo com o encontrado por Meschede et al. (2018). Segundo os autores, houve diferença no número de indivíduos de $E$. Coli entre a estação seca e chuvosa, em poços de escolas em Santarém e Mojuí dos Campos, PA. Os autores atribuem à proximidade dos poços às fossas, sendo a fonte de contaminação.

Silva et al. (2018) realizaram um estudo entorno do lixão de Salinópolis, no Pará, e avaliaram a influência da sazonalidade no número de indivíduos de $E$. Coli em águas subterrâneas e superficiais, o estudo mostrou que no período chuvoso houve maior número de indivíduos, que também foi atribuído à proximidade às fossas, cujo no período chuvoso há a maior percolação, podendo carrear os micro- 
organismos para o aquífero.

O estudo de Lauthartte et al. (2016), observou durante a coleta de amostras de águas subterrâneas na região amazônica, que as fossas negras ou sépticas utilizadas por moradores para o depósito de esgoto doméstico (produtos orgânicos e inorgânicos) são mal construídas e localizadas próximas aos poços, sendo relacionadas à contaminação por coliformes.

\section{CONCLUSÕES}

Os resultados do estudo mostraram que há forte influência da sazonalidade, e a estação chuvosa apresentou as maiores concentrações, sendo de acordo com o encontrado na literatura para a região amazônica. A falta de esgotamento sanitário coloca em risco a população, principalmente, na época de chuva. Os resultados E. Coli na água subterrânea mostraram-se críticos para o abastecimento humano.

Apesar da região ser próxima ao aterro do Perema, ainda não pode concluir que os resultados tiveram influência da pluma de chorume, sendo necessários maiores estudos com interação entre geofísica, geoquímica e geologia da área. O monitoramento da área é necessário, devido à crescente urbanização das comunidades e as precárias condições sanitárias, que provocaram a contaminação do aquífero naquela área. A qualidade dos recursos hídricos amazônicos precisa ser estudada, pois a velocidade de degradação foi muito rápida, nesses últimos anos, assim como, o aumento da urbanização na região Norte do país

AGRADECIMENTOS: Ao Laboratório Tapajós Soluções Ambientais, pela disponibilidade no auxílio nas análises, a Universidade Federal do Oeste do Para - UFOPA, pela concessão e fomento da Bolsa PIBIC/FAPESPA (2018-2019), ao laboratório de Biologia Ambiental da Universidade Federal do Oeste do Pará, e seus colaboradores.

\section{REFERÊNCIAS}

AZEVEDO, R. P.. Uso de água subterrânea em sistema de abastecimento público de comunidades na várzea da Amazônia central. Acta Amazônica, v.36, n.3, 2006. Dol: https://doi.org/10.1590/S0044-59672006000300004 BRASIL. Ministério da Saúde. Portaria n. 2914 de 2011. Brasília: DOU, 2011.

BRASIL. Resolução CONAMA n. 357, de 17 de março de 2005. Dispõe sobre a Classificação dos Corpos de Água e Diretrizes Ambientais para o seu Enquadramento, bem como estabelece as Condições e Padrões de Lançamento de Efluentes, e dá Outras Providências. Brasília: DOU, 2005.

BRASIL. Resolução CONAMA n. 396, de 3 de abril de 2008. Dispõe sobre a classificação e diretrizes ambientais para o enquadramento das águas subterrâneas e dá outras providências. Diário Oficial da República Federativa do Brasil, Brasília, 2008.

BRITTO, F. B.; VASCO, A. N.; NETTO, A. O. A.; GARCIA, C. A. B.; MORAES, G. F. O.; SILVA, M. G.. Surface Water Quality Assesment of the Main Tributaries in the Lower São Francisco River, Sergipe. Brazilian Journal of Water Resources, v.23, e28, 2018. DOI: https://doi.org/10.1590/2318-0331.23182017006

CASTRO, J. S. O.; JÚNIOR, B. T. B. R.; PONTES, A. N; MORALES, G. P.. Potabilidade das águas subterrâneas para o consumo humano na área do polo industrial de BarcarenaPará. Enciclopédia biosfera, Goiânia, v.10, n.19, 2014.

CEBALLOS, B. S. O.. Microbiología Sanitária y Ambiental. In: MENDONÇA, S. R.. Sistemas de Lagunas de Estabilización: cómo utilizar aguas residuales tratadas em sistema de regadíon. Santa Fé de Bogotá: Mc Graw-Hill, 2000. p.68-106.

CONCEIÇÃO, F. T.; MAZZINI, F.; MORUZZI, R. B.; NAVARRO, G. R.. Influências naturais e antrópicas na qualidade da água subterrânea de poços de abastecimento público na área urbana de Marília (SP). Revista Brasileira de Recursos Hídricos, v.19, n.3, p.227-238, 2014. DOI: http://doi.org/10.21168/rbrh.v19n3.p227-238

COSTA, C. L.; LIMA, R. F.; PAIXÃO, G. C.; PANTOJA, L. D. M.. Avaliação da qualidade das águas subterrâneas em poços do estado do Ceará, Brasil. Semina: Ciências Biológicas e da Saúde, v.33, n.2, p.171-180, 2012. DOI: http://doi.org/10.5433/1679-0367.2012v33n2p171 
CRUZ, S. L. F.; GOMES, M. V. C. N.; BLANCO, C. J. V.. Trabalho e resíduos: uma investigação sobre os catadores de lixo de um aterro controlado na Amazônia. Gestão \&

Sustentabilidade Ambiental, v.6, n.2, p.351-367, 2017. DOI: http://doi.org/10.19177/rgsa.v6e22017351-367

DIA, O.; BUELNA, G.; DROGUI, P.; DUBÉ, R.. Hybrid process, electrocoagulation-biofiltration for landfill leachate treatment. Waste Management, v.75, p.391-399, 2018. DOI: http://doi.org/10.1016/j.wasman.2018.02.016

FAÇANHA, E. B.. Avaliação físico-química e microbiológica da qualidade da água de poço consumida no município de Macapá. Monografia (Bacharelado em Ciências Ambientais) - Universidade Federal do Amapá, Macapá, 2016.

FOPPA, C.; KUROSHIMA, K.; MEDEIROS, R. P.; BORGES, S. F.; BARREIROS, M.; ARAÚJO, S. A.; SCHERER, P. F.; LACAVA, L.; BONILHA, L. E. C.. Avaliação da qualidade da água subterrânea e mobilização social: em busca da gestão participativa do uso da água (praia de Taquaras, Balneário Camboriú/SC). In: CONGRESSO BRASILEIRO DE ÁGUAS SUBTERRÂNEAS, 13. Anais. 2004.

FRANÇA, C. L. E.; ANJOS, F. S. C.; ANJOS, D. S. C.; SOUZA, L. S. S.; SOUZA, R. S.; FINAZZI, G. A.; SILVA, A. M. C..

Caracterização físico-química das águas superficiais do Rio São Francisco nos municípios de Juazeiro/BA e Petrolina/PE. Revista Ibero Americana de Ciências Ambientais, v.10, n.6, p.218-230, 2019. DOI: http://doi.org/10.6008/CBPC2179$\underline{6858.2019 .006 .001}$

FREDDO FILHO, V. J. F.. Qualidade das águas subterrâneas rasas do aquífero barreiras: estudo de caso em Benevides/PA. Dissertação (Mestrado) - Universidade Federal do Pará, Belém, 2018.

GRASSHOFF, K.; EHRHARDT, M.; KREMLING, K.. Methods of Seawater Analysis. 2 ed. Weinheim: Verlag Chemie, 1983.

GROTT, S. L.; FAÇANHA, E. B.; FURTADO, R. N.; CUNHA, H. F. A.; CUNHA, A. C.. Variação espaço-sazonal de parâmetros da qualidade da água subterrânea usada em consumo humano em Macapá, Amapá, Brasil. Engenharia Sanitária Ambiental. v.23 n.4,645-654, 2018. DOI: http://doi.org/10.1590/S1413$\underline{41522018162018}$

LAFUENTE, J. G. C.. Química del agua. Madrid: Universidad de Madrid, 1989.

LAUTHARTTE, L. C.; HOLANDA, I. B. B.; LUZ, C. C.; MUSSY, M. H.; PANSINI, S.; MANZATTO, A. G.; YAMASHITA, M.; BASTOS, W. R.. Avaliação da qualidade da água subterrânea para consumo humano: estudo de caso no Distrito de Jaci-Paraná, Porto Velho/RO. Águas Subterrâneas, v.30, n.2, p.246-260, 2016. DOI: http://dx.doi.org/10.14295/ras.v30i2.28547

LI, Y.; LI, J.; DENG, C.. Occurrence, characteristics and leakage of polybrominated diphenyl ethers in leachate from municipal solid waste landfills in China. Environmental Pollution, v.184, p.94-100, 2014. DOI: http://doi.org/10.1016/j.envpol.2013.08.027

MESCHEDE, M. S. C.; FIGUEIREDO, B. R.; ALVES, R. I. S.; SEGURA-MUÑOZ, I. S.. Drinking water quality in schools of the Santarém region, Amazon, Brazil, and health implications for schoolchildren. Ambient \& Água-An Interdisciplinary Journal of Applied Science, v.13, n.6, p.e2218, 2018. DOI: http://doi.org/10.4136/ambi-agua.2218

OLIVEIRA, E. C.; COSTA, K. U. D.; REIS, W. D.; SANTOS, A. A.; SILVA, W. T. P.. Diagnóstico temporal e espacial da qualidade da água superficial em uma microbacia urbana. Revista Ibero-Americana de Ciências Ambientais, v.9, n.8, p.57-69, 2018. DOI: http://doi.org/10.6008/CBPC21796858.2018.008.0006

OLIVEIRA, G.. Biodigestor: uma proposta de aproveitamento do lixo orgânico no município de Santarém. Revista Científica Semana Acadêmica, n.55, 2014.

PAULA FILHO, F. J.; MOURA, M. C. S.; MARINS, R. V.. Fracionamento Geoquímico do Fósforo em Água e Sedimentos do Rio Corrente, Bacia hidrográfica do Parnaíba/PI. Revista Virtual Química, v.4, n.6, p.623-640, 2012.

PEREIRA, A. R.; SANTOS, A. A.; SILVA, W. T. P. FROZZI, J. C.; PEIXOTO, K. L. G.. Avaliação da qualidade da água superficial na área de influência de um lixão. Ambient \& Ague - An Interdisciplinary Journal of Applied Science, v.8, n.3, p.239246, 2013. DOI: http://dx.doi.org/10.4136/ambi-agua.1160

PINHEIRO, D. C.; SALDANHA, E. C.; MONTE, C. N.. Índice de estado trófico e a proveniência do fósforo e clorofila-a em diferentes estações do ano em uma microbacia Amazônica. Revista Ibero Americana de Ciências Ambientais, v.10, n.5, p.89-100, 2019. DOI: http://doi.org/10.6008/CBPC2179$\underline{6858.2019 .005 .0009}$

PORTELLA, M. O.; RIBEIRO, J. C. J.. Aterros sanitários: aspectos gerais e destino final dos resíduos. Direito Ambiental e Sociedade, v.4, n.1, p. 115-134, 2014.

REGADÍO, M.; RUIZ, A. I.; SOTO, I. S.; RASTRERO, M. R.; SÁNCHEZ, N.; GISMERA, M. J.; SEVILLA, M. T.; SILVA, P.; PROCOPIO, J. R.; CUEVAS, J.. Pollution profiles and physicochemical parameters in old uncontrolled landfills. Waste Management, v.32, n.3, p.482-497, 2012. DOI: http://doi.org/10.1016/j.wasman.2011.11.008

SÁ, L. F.; JUCÁ, J. F. T.; MOTTA SOBRINHO, M.. A. Tratamento do lixiviado de aterro sanitário usando destilador solar. Ambient \& Ague - An Interdisciplinary Journal of Applied Science, v.7, n.1, p.204-217, 2012. http://dx.doi.org/10.4136/ambi-agua. 815

SANTOS, A. A.. Qualidade das águas superficiais e subterrâneas na área de influência do aterro sanitário de Cuiabá-MT. Dissertação (Mestrado em Física Ambiental) Universidade Federal de Mato Grosso, Cuiabá, 2008.

SANTOS, A. C.. Noções de Hidroquímica. In FEITOSA, F. A. C. MANOEL FILHO, J.; FEITOSA, E. C.; DEMETRIO, J. G. A.. Hidrogeologia: Conceitos e Aplicações. Fortaleza: CPRM, 2008. p.81-102.

SANTOS, R. C. L.; LIMA, A. S.; CAVALCANTI, E. B.; MELO, C. M.; MARQUES, M. N.. Aplicação de Índices para Avaliação da Qualidade da Água da Bacia Costeira do Sapucaia em Sergipe. Engenharia Sanitária Ambiental, v.23, n.1, p.33-46, 2018. DOI: http://dx.doi.org/10.1590/S141341522017159832 
SEMMA. Secretaria Municipal de Meio Ambiente. Centro Municipal de Informações Ambientais. Informações municipais de Santarém. Santarém: Prefeitura Municipal de Santarém, 2013.

SILVA JUNIOR, M. D.; MORAES, S. R.; VALADÃO, I. C.; PEREIRA, W. S.; MIRANDA, V. B. S.. Análise microbiológica de águas de reservatórios da comunidade do Lixão de Gramacho/Rio de Janeiro. Revista Ibero Americana de Ciências Ambientais, v.10, n.2, p.234-242, 2019. DOI: http://doi.org/10.6008/CBPC2179-6858.2019.002.0020

SILVA, B. B.; ROCHA, L. G.; SILVEIRA, L. P. O.; CARVALHO, A V.; GUIMARÃES, A. P. M.. Análise de qualidade da água do Ribeirão Tranqueira. Revista Ibero-Americana de Ciências Ambientais, v.9, n.8, p.11-25, 2018. DOI: http://doi.org/10.6008/CBPC2179-6858.2018.008.0002

SILVA, C. P.; VARGAS, R. R.; ARRUDA, R. O. M.; ROSINI, E. F.. Efeitos do uso e ocupação da terra na qualidade da água da sub-bacia hidrográfica Cabosol, Guarulhos/SP. Revista Ibero Americana de Ciências Ambientais. v.10, n.6, p.260-273, 2019. DOI: http://doi.org/10.6008/CBPC21796858.2019.006.0023

SILVA, D. P. P.; ANDRADE, N. L. R.; WEBLER, A. D.. Qualidade da água de nascentes urbanas: estudo de caso em microbacia Amazônica, município de Ji-Paraná/RO. Revista Ibero Americana de Ciências Ambientais, v.10, n.3, p.90102, 2019. DOI: http://doi.org/10.6008/CBPC2179$\underline{6858.2019 .003 .0009}$

SILVA, M. L.; BONOTTO, D. M.. Caracterização Hidroquimica na Formação Alter do chão, Município de Manaus (AM). In: JOINT WORLD CONGRESS ON GROUWNDWATTER, 1. Anais. Fortaleza, 2000.

SILVA, M. L.; SILVA, M. S. R.. Perfil da qualidade das águas subterrâneas de Manaus. HOLOS Environment, v.7, n.1, 2007.

SILVA, R. A.; SANTOS, R. C.; FERREIRA, L. O.. Avaliação da concentração de nitrato em águas subterrâneas de poços das regiões de Assis e Marília, São Paulo. Vigilância Sanitária
Debate, v.7, n.2, p.102-106, 2019. DOI:

https://doi.org/10.22239/2317-269x.01290

SILVA, R. S.; CHANG, H. K.. Hidroquímica dos Sistemas Aquíferos Bauru e Guarani na Região Metropolitana de Bauru (SP). Revista Águas Subterrâneas, v.24, n.1, 2010. DOI: http://doi.org/10.14295/ras.v24i1.19648

SIZIRICI, B.; TANSEL, B.. Parametric fate and transport profiling for selective groundwater monitoring at closed landfills: A case study. Waste Management. v.38, n.1, p.263270, 2015. DOI:

http://doi.org.10.1016/j.wasman.2014.12.020

SOUZA, E. B.; KAYANO, M. T.; AMBRIZZI, T.. The regional precipitation over the eastern Amazon/northeast Brazil modulated by tropical Pacific and Atlantic SST anomalies on weekly timescale. Revista Brasileira de Meteorologia, v.19, n.2, p.113-122, 2004.

TANCREDI, A. C. F. N. S.. Recursos hídricos subterrâneos de Santarém: fundamentos para uso e proteção. Tese (Doutorado em Geoquímica) - Centro de Geociências, Universidade Federal do Pará, Belém, 1996.

TSUKAMOTO FILHO, A. A.; CAMPOS, M. N.; VASCONCELOS, L. M. R.; MATOS, S. P.. Diversidade florística de um parque zoobotânico no município de Santarém-Pará. In: Congresso de Ecologia do Brasil, 8. Anais. Caxambu, 2007.

TUCCI, C. E. M.. Regulamentação da Drenagem Urbana no Brasil. Revista da Gestão de água da América Latina, v.13, n.1, p.29-42, 2016. DOI: http://doi.org/10.21168/rega.v13n1.p29-42

VIEIRA, R. M.; SOUZA, D. H.; GODE, J. N.; BITTAR, B. D.; TREVISAN, V.; SKORONSKI, E.. Avaliação do desempenho operacional de uma estação de tratamento de lixiviado de aterro sanitário. Revista Ibero Americana de Ciências Ambientais, v.11, n.1, p.131-145, 2020. DOI: http://doi.org/10.6008/CBPC2179-6858.2020.001.0013

WHO. World Health Organization. PH in Drinking-water. Genebra: WHO, 2003.

A CBPC - Companhia Brasileira de Produção Científica (CNPJ: 11.221.422/0001-03) detém os direitos materiais desta publicação. Os direitos referem-se à publicação do trabalho em qualquer parte do mundo, incluindo os direitos às renovações, expansões e disseminações da contribuição, bem como outros direitos subsidiários. Todos os trabalhos publicados eletronicamente poderão posteriormente ser publicados em coletâneas impressas sob coordenação da Sustenere Publishing, da Companhia Brasileira de Produção Científica e seus parceiros autorizados. Os (as) autores (as) preservam os direitos autorais, mas não têm permissão para a publicação da contribuição em outro meio, impresso ou digital, em português ou em tradução. 